\title{
Assessment of an inner city visual screening programme for preschool children
}

\author{
Tom H Williamson, Rosemary Andrews, Gordon N Dutton, Gordon Murray, \\ Neil Graham
}

\begin{abstract}
Aims-The efficiency of preschool visual screening programmes to detect amblyopia is questionable. In this study such a programme in an inner city was assessed to determine its effectiveness.

Methods-The results of screening and hospital treatment of 712 patients who were considered to require referral were entered into a database for analysis. Default rates were assessed and the efficacy of treatment determined.

Results-The only effective screening test for the detection of amblyopia was visual acuity. A large proportion of referred patients had refractive problems only. High default rates, particularly in geographical areas of lower socioeconomic grading, severely handicapped any attempt to reduce the incidence of amblyopia.

Conclusion-A fresh approach to the detection and care of amblyopia in the inner city community is required, perhaps by performing screening of children in their first year of attendance at school to reduce default rates. Cycloplegic refraction of children who are found to have reduced visual acuity before their referral to hospital is also recommended.

(Br f Ophthalmol 1995; 79: 1068-1073)
\end{abstract}

Amblyopia is a preventable visual disability affecting $1-3 \%$ of the general population and up to $5 \%$ of the preschool age group. It is the commonest disorder encountered in paediatric ophthalmology clinics. ${ }^{1}$ The condition may exclude sufferers from certain occupations and there is a risk of injury to the other eye, the incidence of which has been estimated at 1.75 per 1000 amblyopes, perhaps amounting to 2000 cases in total in the UK. ${ }^{2}$ Strabismic and refractive abnormalities are the commonest causes of amblyopia but are not readily detected by routine infant screening methods. Detection depends upon fortuitous discovery unless a screening programme is in operation. Such screening has been performed on children of school age in the UK since 1908. A recent survey of 165 health authorities in the UK showed that all organised visual testing in schools ${ }^{3}$ but reliance on school eye clinics for the referral of amblyopic patients means that children with amblyopia present later (43\% over the age of 7 years in one study ${ }^{4}$ ) and their amblyopia may be more refractory to treatment. To identify these children earlier, additional preschool visual screening services were commenced by most health authorities. ${ }^{5}$ Such widespread practice has been criticised particularly because of variability in methodology and because of inadequate monitoring of the programmes. ${ }^{6}$

A variety of screening tests is in use because it is unclear which is the best for the detection of visual deficit in this age group. The referral rate to hospital services from screening programmes varies considerably at between $1.4 \%$ and $21.9 \%,{ }^{78}$ and reflects the wide variety of tests, ages of patients, and strategies that are used for screening. Screening systems in the UK have a lack of uniformity and adequate monitoring of results. Assessment of screening programmes (usually in areas with relatively stable populations) has revealed results which are often discouraging with patients commonly defaulting from both screening and treatment, and high false negative and false positive referral rates for amblyopia. ${ }^{9}$

An assessment of a large preschool visual screening programme in an inner city environment comprising a broad spectrum of socioeconomic structures has not hitherto been performed. In this study a programme serving an area of Glasgow was investigated. The aims were to determine both the efficacy of the screening tests and the attendance patterns. The effects of socioeconomic class on attendance and outcome were examined and the outcomes of treatment at discharge were determined.

\section{Patients and methods}

\section{PATIENTS}

A preschool visual screening programme examining 3.5 to 4.5 -year-old children was commenced in 1979 in the north west area of Glasgow. Between 1979 and 1982 lists of children were obtained from local health visitors. Thereafter a community health index was used to obtain names and addresses. The children were examined by orthoptists in local health clinics. A description of the screening procedure can be seen in Table 1 and the criteria for 
Table 1 The history obtained and tests performed during the screening procedure

History

Family history of strabismus, spectacles, or amblyopia

Visual acuity testing with Sheridan Gardiner singles charts at 6 metres

Cover test at $33 \mathrm{~cm}$ and 6 metres

Ocular movements

Fusion testing with a 20 dioptre base out prism

Stereo testing with randot circles or TNO testing

referral for further examination at the ophthalmology clinic are shown in Table 2 . A second screening examination was performed if there was doubt as to whether referral was indicated.

The screening service was designed prospectively with set guidelines and referral procedures to facilitate later analysis. The findings at screening and on subsequent attendance at hospital were recorded on specially designed cards.

In order to assess the results retrospectively a database was designed on FOXPRO 2 software on an IBM compatible PC which provided ease of input of the data from the cards from years 1979 to 1987 . Specially designed screens which automatically coded the data numerically in the database for future statistical analysis were employed to facilitate data entry. Eighty two fields of information, in the categories shown in Table 3, were recorded for each patient.

Two alternative definitions of amblyopia were applied because of the ambiguity about the degree of visual acuity deficit required. Firstly, a value was used with visual acuity in either eye worse than $6 / 9$, or a difference in vision between the two eyes of one patient of two lines or more on the Snellen chart (definition A). A second definition of $6 / 9$ or worse in either eye was also used (definition B).

For those patients who were referred, the parent was asked to administer atropine $1 \%$ twice daily for 3 days before the child's hospital appointment. After refraction was performed by an ophthalmologist at the first visit to hospital the patient was prescribed glasses if amblyopia or strabismus was present or if the refraction was more than +4 dioptres sphere. The Snellen visual acuity from the subsequent visit with the glasses was taken as the baseline visual acuity for defining amblyopia. This result was used to evaluate the screening tests and also for the assessment of subsequent treatment. If a Snellen acuity was unavailable for example, only Kay's measure of visual acuity was available, the patient was excluded

Table 2 The criteria for the referral of patients from the screening service to the hospital

Visual acuity of $6 / 9$ or less in either eye (including an obviously
struggling $6 / 6$ vision)
OR
Squint
OR
Abnormality of ocular movements
OR
Family history
OR
A lack of response to the 20 dioptre prism test
OR
Negative response to stereo test

from the analysis involving the definitions of amblyopia (86 patients excluded).

To assess the efficacy of the screening test for the detection of amblyopia, the proportions of the patients with normal and abnormal tests were plotted against the visual acuity at baseline for the worse eye. From these plots the true positive and false positive rates for each test for both definitions of amblyopia were calculated and expressed as percentages. The false negative rate and true negative rate are unknown because the patients who were screened and who were not referred to hospital were not re-examined.

Stepwise logistic regression was used to determine a model for the detection of amblyopia by the screening tests (visual acuity in the worse eye, cover test, $\mathrm{A} / \mathrm{V}$ phenomenon, $20 \mathrm{D}$ prism test, eye movements, convergence, and family history) to determine the most efficient combination of screening tests. To investigate the pattern of attendance, patients were recorded as having completed the programme, or as having defaulted from the first or later hospital visits. In addition, those patients who were referred elsewhere were recorded.

The socioeconomic groupings for the postal codes were obtained (based upon a 1981 census, Greater Glasgow Health Board) and allowed three classifications of socioeconomic class to be used to allow assessment of the influence of this on default rates. ${ }^{10}$

For social class 1 Glasgow postal codes G61 and $\mathrm{G} 62$ were included; for social class 2: G11, G12, G13, G33, G43, G60, G66, G73, and G81; for social class 3: G3, G4, G14, G15, G20, G51, G52, and G53. There were 209 patients in class 1, 235 patients in class 2 , and 243 patients in class 3 . Using stepwise logistic regression the variables influencing nonattendance including sex, diagnosis, socioeconomic class, and visual acuities at baseline (definitions A and B) were tested.

\section{Results}

\section{GENERAL DATA}

From the birth rates in the areas and the numbers of addresses obtained from the health visitors or community health index it was estimated that between $87-90 \%$ of the child population of the areas involved were sent appointments, with a mean of 1588 children for each year (minimum 890 and a maximum of

Table 3 The categories of information for which fields of data were recorded for the patients referred from screening

(1) General information - for example, sex and age

(2) Visual acuities recorded at screening, at presentation, at attendance, and at the last visit to hospital

(3) Screening variables

(4) Refraction results

(5) Number of visits involved

(7) Results of fusion tests

(8) Cover tests

(9) Measurements at the last visit to the hospital including variables in categories two, five, seven, and eight

(10) Default/referral/follow up rate

(11) Results of teenage follow up (for a future presentation)

(12) Dates

(13) Postal codes 
Table 4 Diagnoses of the patients who were examined at the hospital after referral from the screening service

\begin{tabular}{lc}
\hline Diagnosis & Number \\
\hline No abnormality detected or defaulted & 184 \\
Strabismus & 8 \\
Esotropia & 63 \\
Esotropia and ammetropia & 10 \\
Exotropia & 6 \\
Exotropia and ammetropia & 50 \\
Microtropia (esotropia) & 4 \\
Microtropia (exotropia) & 71 \\
Refraction & 29 \\
Hypermetropia & 182 \\
Myopia & 68 \\
Astigmatism & \\
Anisometropia & 11 \\
Others & 7 \\
Eye movements & 11 \\
Esophoria & 3 \\
Exophoria & 5 \\
Consecutive strabismus & \\
Brown's syndrome & \\
\hline
\end{tabular}

2543). The mean attendance at screening was only $57 \%$ (range $52-64 \%$ ) providing a total of 8142 children seen over the 9 year period (mean of 904 per year). A mean of $10 \%$ of the children who were screened were referred each year to the hospital service, making a total of 863 children. The records for 757 patients were available but 45 were not included in the analysis because they had previously attended ophthalmology departments and therefore were not new diagnoses at the time of screening.

Records for 712 patients were evaluated and comprised 361 males and 351 females at the average age of 4.1 (SD 0.6$)$ years at presentation. The diagnoses for these patients are shown in Table 4. For these patients 4406 hospital orthoptic visits (a mean of 6.2 per patient) and 2037 visits to the ophthalmologist $(2 \cdot 8$ per patient) were required. Twenty eight operations were performed requiring 84 inpatient days, $3 \cdot 2$ days per operation. Sixty per cent of the patients attended the full visual treatment programme, $33 \%$ did not complete the programme, and 7\% were referred to other hospitals. Of all the patients who attended the hospital at least once $29 \%$ suffered from strabismus and $48 \%$ from refractive problems (without strabismus). Also, $68 \%$ of the patients who attended at least once had amblyopia (definition A) - 426 patients in total.

Of the amblyopes, $58 \cdot 2 \%$ had a refractive aetiology, $26.5 \%$ strabismus $(43.3 \%$ of these were microtropias), and $8 \cdot 2 \%$ unknown aetiology. Sixty five per cent of the amblyopes

Table 5 The percentage of patients with abnormal screening test results who had amblyopia (true positives) and the percentage with abnormal results who did not have amblyopia (false positives) for the various tests employed in visual screening using definition $A$ of amblyopia - that is, visual acuity $(V A)$ of less than 6/9

\begin{tabular}{|c|c|c|c|c|}
\hline \multirow[b]{2}{*}{ Screening test } & \multirow[b]{2}{*}{$n$} & \multicolumn{3}{|c|}{ Baseline visual acuity } \\
\hline & & $\begin{array}{l}\text { Worse than 6/9 } \\
\text { (true +ve) (\%) }\end{array}$ & $\begin{array}{l}\text { 6/9 Or better } \\
(\text { false +ve) (\%) }\end{array}$ & $\begin{array}{l}\% \text { Of total } \\
\text { (all +ves) }\end{array}$ \\
\hline $\begin{array}{l}\text { VA worse than } 6 / 6 \\
\text { VA worse than } 6 / 9 \\
\text { Cover test } \\
20 \mathrm{D} \text { prism test } \\
\text { Convergence } \\
\text { Eye movements } \\
\text { A/V phenomenon } \\
\text { Stereopsis } \\
\text { Family history of: }\end{array}$ & $\begin{array}{l}566 \\
566 \\
574 \\
534 \\
542 \\
574 \\
574 \\
510\end{array}$ & $\begin{array}{r}98 \cdot 8 \\
82 \cdot 7 \\
30 \cdot 2 \\
18 \cdot 8 \\
5 \cdot 0 \\
11 \cdot 1 \\
2 \cdot 0 \\
31 \cdot 0\end{array}$ & $\begin{array}{r}87 \cdot 6 \\
46 \cdot 9 \\
17 \cdot 3 \\
7 \cdot 3 \\
3 \cdot 9 \\
6 \cdot 5 \\
6 \cdot 5 \\
10 \cdot 5\end{array}$ & $\begin{array}{r}92 \cdot 2 \\
62 \cdot 3 \\
22 \cdot 9 \\
11 \cdot 3 \\
4 \cdot 7 \\
8 \cdot 1 \\
4 \cdot 5 \\
19 \cdot 2\end{array}$ \\
\hline $\begin{array}{l}\text { Amblyopia } \\
\text { Spectacles } \\
\text { Squint }\end{array}$ & $\begin{array}{l}413 \\
516 \\
512\end{array}$ & $\begin{array}{l}31 \cdot 2 \\
75 \cdot 7 \\
37 \cdot 2\end{array}$ & $\begin{array}{l}17 \cdot 5 \\
71 \cdot 4 \\
24 \cdot 4\end{array}$ & $\begin{array}{l}23 \cdot 2 \\
73 \cdot 3 \\
28 \cdot 3\end{array}$ \\
\hline
\end{tabular}

Table 6 The percentage of patients with abnormal screening test results who had amblyopia (true positives) and the percentage with abnormal results who did not have amblyopia (false positives) for the various tests employed in visual screening using definition $B$ of amblyopia - for example, visual acuity (VA) of less than 6/6

\begin{tabular}{lll}
\hline & \multicolumn{2}{c}{ Baseline visual acuity } \\
\cline { 2 - 3 } Screening test & $\begin{array}{c}\text { Worse than 6/6 } \\
(\text { true }+ \text { ve) (\%) }\end{array}$ & $\begin{array}{l}6 / 6 \text { Or better } \\
\text { (false }+ \text { ve) (\%) }\end{array}$ \\
\hline VA worse than 6/6 & $97 \cdot 2$ & $74 \cdot 8$ \\
VA worse than 6/9 & $70 \cdot 6$ & $38 \cdot 5$ \\
Cover test & $23 \cdot 5$ & $21 \cdot 2$ \\
20 D prism test & $12 \cdot 8$ & $8 \cdot 2$ \\
Convergence & $2 \cdot 5$ & $7 \cdot 9$ \\
Eye movements & $8 \cdot 5$ & $7 \cdot 1$ \\
A/V phenomenon & $2 \cdot 6$ & $11 \cdot 0$ \\
Stereopsis & $21 \cdot 2$ & $12 \cdot 2$ \\
Family history: & & $13 \cdot 9$ \\
$\quad$ Amblyopia & $25 \cdot 7$ & $67 \cdot 2$ \\
Spectacles & 74.9 & 28.6 \\
Squint & $28 \cdot 2$ & \\
\hline
\end{tabular}

completed the full treatment protocol. The allocation of hospital services for those patients who failed to complete the programme was 609 visits to orthoptist, 332 visits to doctor, and 21 inpatient days.

\section{SCREENING TESTS}

Tables 5 and 6 show that the visual acuity recorded at the time of screening predicts, with a high true positive rate, those patients with amblyopia, but there is a high false positive rate when all of the patients with worse than $6 / 6$ visual acuity are considered. The false positive rate is reduced when only those with worse than $6 / 9$ are considered but with a reduction of accompanying true positives. The other tests used in screening add little to the prediction of amblyopia because they are abnormal in smaller proportions of the population. Stepwise regression analysis for both definitions of amblyopia showed that for definition A, only visual acuity, family history of amblyopia, and stereopsis provide predictive power; and for definition B, visual acuity, cover test, convergence, and family history of spectacles.

Visual acuity was the most significant variable in each case with the other variables only adding a little additional information to the models if visual acuity was included. If the cut off of worse than $6 / 9$ visual acuity was used for referral of patients from screening, amblyopia (at definition A) was detected at a true positive rate of $82.7 \%$ and a false positive rate of $46.9 \%$. However, if visual acuity had been the only means of screening, 48 cases of 'non-amblyopic' manifest strabismus and 101 patients with refractive errors (and no squint or

Table 7 The number of patients with each diagnosis who would not have been referred had visual acuity alone been used in screening (referring with visual acuity of less than 6/9)

\begin{tabular}{lr}
\hline Strabismus & 48 \\
Esotropias & 25 \\
Exotropias & 10 \\
Micro-esotropias & 13 \\
Refractive error only & 10 \\
Abnormal eye movements & 6 \\
Esophoria & 13 \\
Exophoria & 20 \\
Convergence deficiency & 1 \\
Brown's syndrome & 3 \\
No abnormality & 93 \\
\hline
\end{tabular}


Table 8 The numbers of patients (and percentages) in each socioeconomic class who completed the treatment programme (Complete), who defaulted (Default), and who were referred to other centres for further management (Referred)

\begin{tabular}{lcccr}
\hline \multirow{5}{*}{ Follow up } & Socioeconomic class (\%) & & \\
\cline { 2 - 5 } & Upper (1) & Middle (2) & Lower (3) & Total \\
\hline Complete & $151(72 \cdot 2)$ & $148(63 \cdot 0)$ & $116(47 \cdot 7)$ & 415 \\
Default & $49(23 \cdot 4)$ & $71(30 \cdot 2)$ & $105(43 \cdot 2)$ & 225 \\
Referred & $9(4 \cdot 3)$ & $16(6 \cdot 8)$ & $22(9 \cdot 1)$ & 47 \\
Total & $209(100)$ & $235(100)$ & $243(100)$ & 687 \\
\hline
\end{tabular}

amblyopia) would have been missed. Table 7 shows the diagnoses of patients who would not have been referred if visual acuity of worse than $6 / 9$ alone was used.

\section{DEFAULT RATES}

Table 8 shows the breakdown by geographic socioeconomic class of the percentages of patients who had full follow up, who defaulted, and those that were referred elsewhere. The default level increased as socioeconomic status fell. Stepwise regression analysis determined that socioeconomic class was the only variable to significantly affect the attendance rate. The probability of non-attendance from the model was $20.5 \%$ for classes 1 and 2 , and $37 \cdot 1 \%$ for class 3 . Figure 1 shows that median visual acuity improved only in those who continued to attend the treatment programme and not in those who defaulted. The percentages of patients in whom the visual acuity improved, remained stable, or deteriorated in the worse eye according to whether they completed the treatment protocol or not are shown in Figure 2. Unbalanced repeated measures implied that children in the default group remained amblyopic whereas those in the follow up group recovered visual acuity.

Table 9 shows that the patients who had strabismus were more likely to have poorer visual acuity at the end of treatment than patients with refractive problems or other diagnoses. This was confirmed by logistic regression analysis.



Figure 1 The percentages of patients who showed a deterioration in visual acuity, stable acuity, or improved acuity for the patients who completed the treatment programme (Completed) and those who defaulted (Defaulted).

\section{Discussion}

The provision of a preschool visual screening programme requires the allocation of suitable resources, time, and effort and its use should not be embarked upon lightly. In the UK $74.8 \%$ of orthoptic departments are providing some sort of preschool visual screening, the majority $(88 \%)$ screening in the 3-4 year age group. ${ }^{5}$ In the USA it is estimated that $21 \%$ of children receive preschool screening. ${ }^{11}$ The non-attendance rate discovered in this study is a cause for concern because at each step of the screening and treatment programme there was a significant section of the population who defaulted from care. Thus at the end of the visual screening programme a very much smaller section of the population has been effectively treated than was initially intended. In our study, although a large number of children were seen through the 9 year period (a total of 8142), there was a large section of the population that was not screened either because they were not reached via the community health index ( $10 \%$ of the population) or because they did not attend the screening examination $(43 \%$ of those sent appointments). From the $10 \%$ of patients referred on to the hospital, $4 \%$ subsequently defaulted from the first hospital visit; thereafter $32 \%$ defaulted from the full treatment programme. The mounting percentage of the population who therefore do not receive effective screening or full treatment is high (Figure 3). The rates for this inner city population appear to be higher than have been reported from other communities in the UK such as Canterbury with 24 to $29 \%$ defaulting from attending the screening examination, ${ }^{12}$ Cornwall with 25 to $28 \%$ not attending screening and $3 \cdot 7 \%$ not attending the hospital appointment, ${ }^{8}$ and $\mathrm{Ayr}$ where only $14 \%$ of the children sent for did not attend for screening. ${ }^{13}$ The differences in the results may reflect the different geographical areas involved and their socioeconomic

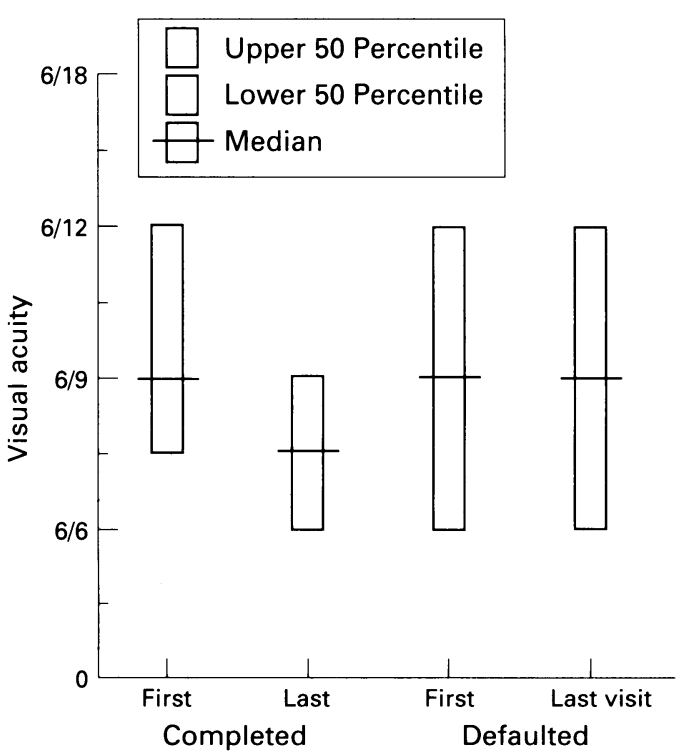

Figure 2 The median visual acuities (and 25 and 75 percentiles) at the first and last visit to the treatment programme for the patients who completed the treatment programme (Completed) and those who defaulted (Defaulted). 
Table 9 The percentages of patients with each level of visual acuity for the diagnosis groupings. The results are for the last visit of the patients who completed the treatment programme

\begin{tabular}{llllc}
\hline Visual acuity & $\begin{array}{l}\text { No abnormality } \\
(n=91)\end{array}$ & $\begin{array}{l}\text { Strabismus } \\
(n=86)\end{array}$ & $\begin{array}{l}\text { Refractive error } \\
(n=219)\end{array}$ & $\begin{array}{c}\text { Other } \\
(n=26)\end{array}$ \\
\hline $6 / 7 \cdot 5$ at least & $71 \cdot 4$ & $25 \cdot 6$ & $63 \cdot 9$ & $80 \cdot 8$ \\
$6 / 7 \cdot 5$ to $6 / 18$ & $28 \cdot 6$ & $45 \cdot 3$ & $33 \cdot 8$ & $11 \cdot 5$ \\
$6 / 18$ or worse & 0 & $29 \cdot 0$ & $2 \cdot 2$ & $7 \cdot 6$ \\
\hline
\end{tabular}

composition and the differing methodologies employed.

In this study, the socioeconomic class of the patients had a strong bearing on the default rate from the service despite the use of local health clinics. It may be that different approaches will be required for different areas - for example, mobile screening services. ${ }^{14}$ As a group, patients who default do not perform well but still require allocation of substantial resources.

It has not been possible from the design of this study to determine the false negative referral rate for the screening service. However, other investigators have attempted to do this and have found $7 \%$ to $38 \%$ false negative referral rates ${ }^{15} 16$ which provides a further indication of the inefficiency of screening preschool children. Moreover a significant proportion of individuals who are referred through screening are already attending the hospital service. This comprised $26 \%$ of patients in one study ${ }^{15}$ and $6 \%$ of the patients referred to hospital in our study. The relatively small proportion of potential amblyopes who are therefore identified and successfully treated has led some to argue that current programmes do not have much impact upon the incidence of amblyopia in our society. Studies in Scandinavia suggest that the incidence of amblyopia has reduced since the commencement of screening services for children ${ }^{17}$ but an article looking at the incidence of amblyopia in recruits to the British Army found no convincing change from an incidence of $4.7 \%$ males in 1965 to $4 \cdot 1 \%$ in $1976 .{ }^{18}$

School visual screening programmes have been criticised because of late referral and the risk this poses to effective treatment for the amblyopia. ${ }^{6}$ Arguments have been made to remove the school screening service from the system, therefore allowing for reallocation of resources. ${ }^{3}$ The findings of this study in which preschool screening was found to be inefficient do not support the cessation of school screening. It should be easier to examine all of the children

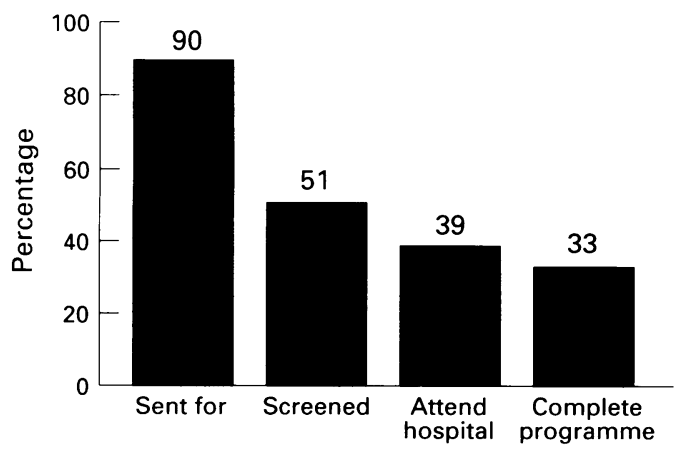

Figure 3 The percentage of individuals who continue to attend at each step in the screening programme. in a geographical area by screening at school. It may be that screening should be performed at the first year of attendance of children to school particularly as patching therapy has been shown to be effective after the age of $8 .^{9}$ In the inner city environment it may be better to reach a high proportion of the amblyopes in the population by screening them out at school (albeit with the disadvantage of starting treatment later) than reaching a small proportion of these individuals through preschool screening (with its inherent inefficiencies).

If the principal aim of screening is to detect amblyopia (and not other abnormalities without amblyopia, in particular refractive problems which was the largest group detected, $48 \%$ ), the tests that are currently used are inefficient. Our analysis supports the work of others who have advocated a simplified screening programme ${ }^{7} 19$ based on visual acuity. Even this test is inefficient with many false positives being referred; and hyperacuity tests and logmar tests of visual acuity may be required..$^{20} 21$ The other tests employed in our study added little to the identification of amblyopia. The findings are consistent with the work of others who have found that no other tests can replace visual acuity assessment. ${ }^{17} 21$ If, however, visual acuity was used at its most efficient (a cut off of worse than 6/9) some patients with ocular abnormalities which have not yet caused amblyopia may be missed. For example, the prescription of spectacles for patients with good vision and strabismus may have prevented the development of amblyopia in these individuals.

Abnormal refraction was the commonest anomaly detected in the patients screened and measurement of refraction should be considered, perhaps in a simplified form, if screening is to be made more effective. ${ }^{22}$ Indeed, a call for refraction has been made by many other investigators in the past. ${ }^{152-24}$ In this study, a large number of patients with refractive problems without amblyopia were referred to hospital. These could have been dealt with elsewhere - for example, by opticians in the community. We cannot say whether the early detection of these refractive problems and their subsequent treatment means that the occurrence of amblyopia in some children was prevented, but it is arguable whether hospital attendance is required for these patients.

In conclusion, there were very high default rates from an inner city preschool visual screening programme which severely handicapped any attempt to reduce the incidence of amblyopia. The only effective test currently performed in screening for amblyopia is visual acuity but this was also not particularly efficient. The high incidence of refractive problems without strabismus suggests again that there is a need for refraction to be performed earlier in the screening protocol, perhaps as a routine in those children found to have reduced visual acuity.

\footnotetext{
Taylor D. Screening? Trans Ophthalmol Soc U K 1985; 104: $637-40$.

2 Tommila V, Tarkkanen A. Incidence of loss of vision in the healthy eye in amblyopia. Br $\mathcal{F}$ Ophthalmol 1981; 65: $575-7$.
} 
3 Stewart-Brown SL, Haslum M. Screening of vision in school: could we do better by doing less? BMF 1988; 297:

4 Ingram RM. The role of the school eye clinic in modern ophthalmology. $B M \mathcal{F} 1973 ; 1: 278-80$

5 Stewart-Brown SL, Haslum MN, Howlett B. Preschool vision screening: a service in need of rationalisation. Arch Dis Child 1988; 63: 356-9.

6 Health for all children. A programme for child health surveillance. Oxford: Oxford University Press, 1989.

7 Dholakia S. The application of a comprehensive visual screening programme to children aged 3-5 years. Can a modified procedure be devised for visual screening a modified procedure be devised for visual screening
by ancillary staff? Ophthal Physiol Opt 1986; 7: $469-76$

8 Wormald RPL. Preschool vision screening in Cornwall: performance indicators of community orthoptists. Arch Dis Child 1991; 66: 917-20.

9 Oliver M, Neumann R, Chiamovitch Y, Gatesman N, Shimshoni M. Compliance and results of treatment for amblyopia in children more than 8 years old. $A m \mathcal{F}$ Ophthalmol 1986; 102: 340-5.

10 McCarron PG, Davey-Smith G, Wormsley JI. Deprivation and mortality in Glasgow: changes from 1980 to 1992 BMF 1994; 309: 1481-2.

11 Ehrlich RS, Reinecke RD, Simons K. Preschool visual screening for amblyopia and strabismus: programs, methods, guidelines, 1983. Surv Ophthalmol 1983; 28: 145-63.

12 Edwards RS, Whitelaw AJ, Abbott AG. Orthoptists as preschool screeners: a 2 year study. Br Orthopt $f 1989$; 46: 14-9.
13 Cameron JH, Cameron M. Visual screening of preschool children. BMF 1978; 2: 1693-4

14 MacLellan AV, Harker P. Mobile orthoptic service for primary screening of visual disorder in young children. $B M F$ 1979; 1: 994-5.

15 Ingram RM, Holland WW, Walker C, Wilson JM, Arnold PE, Dally S. Screening for visual defects in preschool children. Br f Ophthalmol 1986; 70: 16-21.

16 DeBecker I, MacPherson HJ, LaRoche GR, Braunstein J, Cottle R, McIntyre LL, et al. Negative predictive value of a population-based preschool vision screening program. Ophthalmology 1992; 99: 998-1003.

17 Maslin K, Hope C. Photoscreening to detect potential amblyopia. Aust NZ Z Ophthalmol 1990; 18: 313-8.

18 Hopkinson B, Clarke JR, Oelman BJ. Residual amblyopia in recruits to the British Army. BMF 1982; 285: 940.

19 Ingram RM. The problem of screening children for visual defects. Br f Ophthalmol 1977; 61: 4-7.

20 Flynn JT. Amblyopia revisited. $\mathcal{f}$ Pediatr Ophthalmol Strabismus 1991; 28: 183-99.

21 Leguire LE, Rogers GL, Bremer DL, Wali N. A comparison of contrast sensitivity functions (CSF) between strabismic and anisometropic amblyopia in children. Binoc Vision Quart 1989; 4: 179-86.

22 Olver JM. Simple retinoscopic screening. Eye 1988; 2: 309-13

23 Ingram RM. Screening children for visual defects. $B M F$ 1977; 1: 594-5.

24 Ingram RM, Walker C. Refraction as a means of predicting squint or amblyopia in preschool siblings of children known to have these defects. Br F Ophthalmol 1979; 63: 238-42. 